\title{
Insulation systems for structures on pile supports
}

\author{
Aleksey Zhukov ${ }^{1,2,3, *}$, Igor Bessonov ${ }^{2}$, Andrey Medvedev ${ }^{1,4}$, Ekaterina Zinovieva ${ }^{1}$, and \\ Elizaveta Mednikova ${ }^{1,3}$ \\ ${ }^{1}$ Moscow State University of Civil Engineering, 129337, 26, Yaroslavskoe shosse, Moscow, Rus-sia \\ ${ }^{2}$ Research Institute of Building Physics of the Russian Academy of Architecture and Building, \\ 127238, Lokomotivny pr. 21, Moscow, Russia \\ ${ }^{3}$ Higher School of Economics University, 101000, 20 Myasnitskaya Ulitsa, Moscow, Russia \\ ${ }^{4}$ Russian State Geological Prospecting University, 117997, Miklukcho-Maklaya, 23, Moscow, Russia
}

\begin{abstract}
Construction on problem soils or in permafrost conditions involves using of pile foundations with a ventilated space under the floor structure. In this case, additional thermal insulation is required under the first-floor structure (above the ventilated space). This problem is compounded by construction in cold regions. The goal of research was to develop insulation systems for buildings on pile foundations for different climatic zones, including conditions of the arctic region and other regions with a predominance of ever-frozen ground. With the help of the THERM computer program, the conditions of bidimensional heat interchange in the enclosing structures of a building with pile foundation were simulated. The construction of such buildings is practiced on problem soils. The resulting models were analyzed in terms of the thermophysical characteristics of the structures. As a result, the optimal version of the insulation system was chosen, effective both in the climatic conditions of the midland and in the especially cold conditions of Yakutia and Trans-Polar region (The Subarctic). This system included insulation with mineral wool slabs along the facade walls, with extruded polystyrene (XPS) foams along the basement part and the floor structure, and with roll polyethylene (PE) foams (with the formation of a seamless insulation shell) along the ventilated space under the floor structure and above, on top of insulation boards.
\end{abstract}

\section{Introduction}

The minimum permissible heat transfer resistance of walls and coverings of buildings for various purposes and different climatic conditions is regulated by SP 50.13330-2012 and it is de-termined by the operating conditions of the insulation systems, including atmospheric manifesta-tions [1-3]. During the reconstruction of walls and coverings, the thickness of the additional thermal insulation layer was determined based on the difference between the required and exist-ing heat transfer resistances.

\footnotetext{
* Corresponding author: 1j211@yandex.ru
} 
The effective use of thermal insulation is based on the following conditions. Firstly, the thermal insulation material is used only dry or at the equilibrium moisture content. Any excessive moistening of the structure leads to an increase in the thermal conductivity of the insulating layer and a sharp drop in the real thermal resistance. Secondly, the installation of insulation boards must be close to each other and to the structural element. The appearance of a gap between the boards is not allowed due to leading to the formation of thermal bridge, which will increase heat loss through the enclosing structure [4-6].

Moisture can enter building structures in various ways. The movement of the vapour-air mixture occurs constantly in the construction of the basement part of the wall and foundation. Moisture condensation is possible under certain conditions, for example, when the temperature in the material reaches the dew point. Capillary rise of ground moisture through the foundation structure and through the capillaries of the wall material can occur if the insulation system is in-correctly performed. All these reasons make it advisable to use seamless heat-vapor-waterproofing shells [7-9] in building insulation systems.

\section{Materials and methods}

Insulation systems for residential buildings for the Arctic region have a number of significant features, the main of which are installations allowing to preserve permafrost. Preservation of the soil in a frozen state implies either the use of floating foundations (like the "Swedish slab"), which is not effective for residential buildings (heat escapes through the floor, the soil thaws and loses its bearing capacity), or construction on pile foundations, which is used everywhere [10-11].

The insulation diagram of a residential building with a pile foundation is shown in Fig.1. The insulating wall cladding is made according to the technology of insulated plaster facades (EIFS), and the floor structure above the ventilated space is insulated with several layers of XPS boards laid with offset joints.

Such an insulation system has two negative factors, these are cold bridges at the joints of the slabs (displacement during installation allows to reduce heat losses, but not completely) and, most importantly, a serious channel of heat transfer between the joint of thermal insulation plates and enclosing structures (see Fig.1a). The joint is not only an area of active conductive heat transfer, but also a path for infiltration of cold air through leaks in the placement of slabs and their abutment to structures.

At significant negative outside temperatures (from minus $30{ }^{\circ} \mathrm{C}$ and below), the perimeter of the building in its lower basement part remains in the area of negative temperatures, which is extremely undesirable, both from the point of view of the formation of a comfortable microclimate in the premises, and from the point of view of the durability of the structure, freezing to the full thickness. At the same time, the thickness of the thermal insulation laid along the overlap can reach $500 \mathrm{~mm}$.

The experience of using foamed polyethylene in central Russia made it possible to formulate recommendations for the formation of an effective insulating coating [12-14]. It is important that the basic principles of the technology based on mechanical fastening of insulating sheets (rolls) and welding of their joints with hot air have already been implemented at dozens of facilities throughout the country.

Rolled polyethylene foam with a reflective coating (foil or with a metallized film) forms a protective layer along the outer perimeter of the structure, and is the basis of a floating floor laid along XPS insulating boards. With a thickness of XPS-thermal insulation of 200 $\mathrm{mm}$ and a thickness of UPF (PE) -insulating coating of $20 \mathrm{~mm}$, the thermal resistance of the insulating circuit is not less than $4.0 \mathrm{~m}^{2 \circ} \mathrm{C} / \mathrm{W}$, at the same time, the thermal uniformity of the structure along the surface is significantly increases and the paths of infiltration of cold air are completely excluded. 

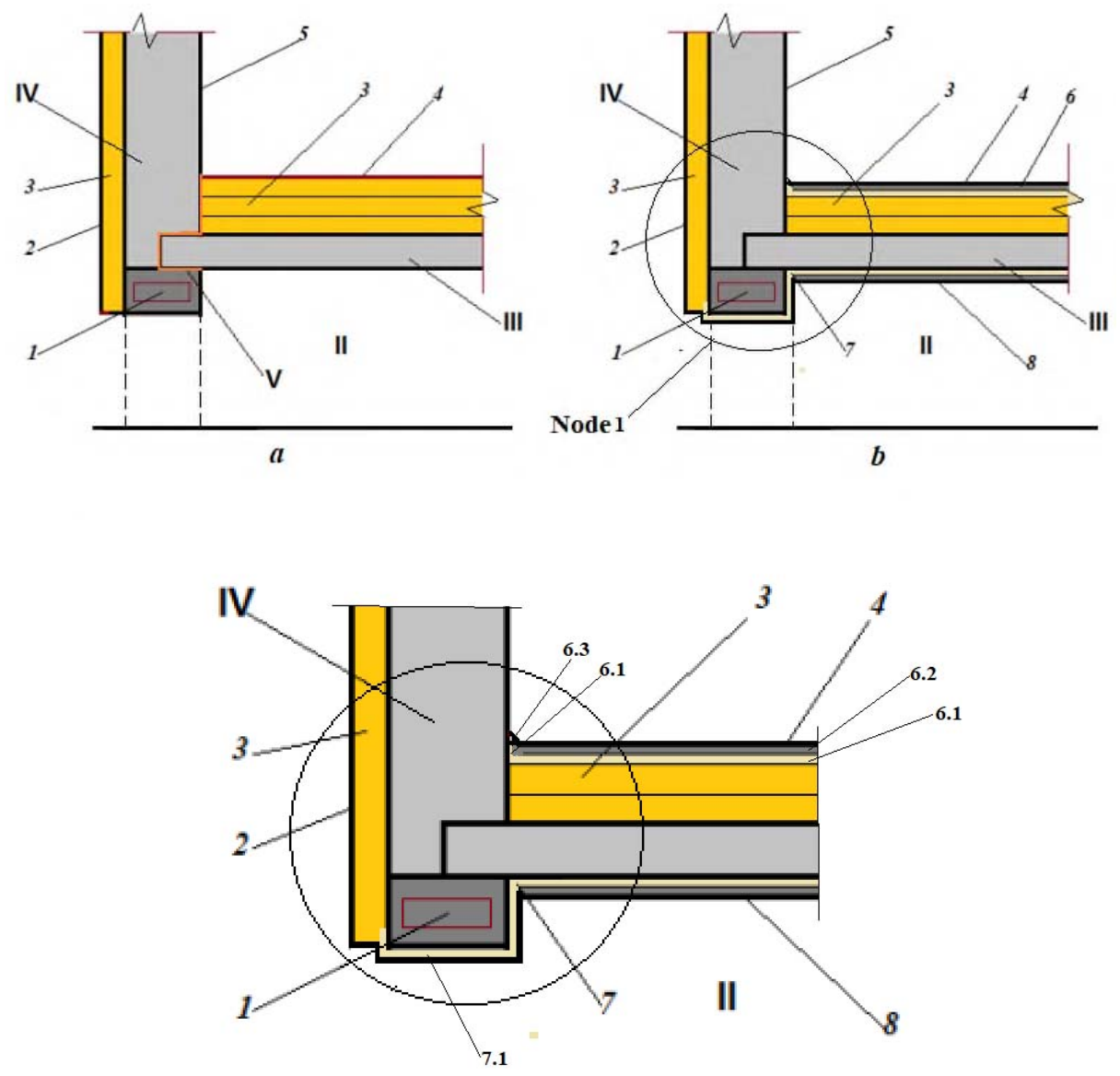

Fig.1. The floor structure of residential building diagram (section 2 - wall between columns and detailing node 1): $a$ - without insulation of the floor structure over the ventilated space; $b$ - with insulation of the floor structure over the ventilated space; I - column; II - ventilated space; III- the floor structure over the ventilated space; IV - bearing wall; $\mathrm{V}$ - area of increased heat transfer and cold air infiltration; 1 -binding of columns; 2 - facade insulation system; 3 - XPS thermal insulation board; 4 - top coat of floor; 5 - interior wall cladding; 6 - floating floor system (dry build), includes: 6.1 - EPE foam layer $20 \mathrm{~mm}$ thick, installed on the wall; 6.2 - chrysotile cement sheet $10 \mathrm{~mm}$ thick (or fiber cement sheet), then the top coat of floor; 6.3 - floor molding; 7 -insulation above the ventilated space; 7.1 - insulation before EIFS (completely blocks the infiltration flow at the junction); 8 - protective lining.

The program for calculating temperature fields for the THERM computer, which meets the requirements of set of rules SR 50.13330.2012, contributes to the study of heat transfer processes. Using the program makes it possible to simulate 2D heat transfer in building components such as windows, walls, floors, roofs and doors. The analysis of heat transfer using the program allows you to evaluate the energy efficiency of the structure and the local temperatures of the sample, allowing you to solve problems with condensation, moisture content of the structure material and its tightness. 
The program version includes several additional technical characteristics and user interface features. The most important of them is the radiative heat transfer algorithm taking into account mutual irradiation and shading of the calculated surfaces. This ability increases the computational accuracy in situations where non-planar surfaces are analyzed that have different temperatures and exchange energy through radiative heat transfer.

\section{Results}

The insulating cladding of the walls is made according to the technology of insulated plaster facades (SFTC), and the ceiling over the ventilated space is insulated with several layers of XPS-plates, laid with offset joints. Insulation made of rolled polyethylene foam is mounted along the entire base (under the overlap) and installed on the wall up to the basement part of the SFTC. Thus, rolled polyethylene foam with a metallized coating completely blocks the infiltration flow at the junction of the wall ceiling. Separate rolls of polyethylene foam are mounted in the lock, followed by welding the joint with hot air using a construction hair dryer. Considering that polyethylene foam has not only low thermal conductivity, but also very low vapor, moisture and wind permeability, we can say that a seamless insulating shell is formed.

The implementation of computer calculations was aimed at assessing the distribution of temperature fields and thermal resistance of insulation systems operating in different temperature conditions.

The calculations used the following input data:

The strapping of the columns was carried out with reinforced concrete half-timbered timber (density $2400 \mathrm{~kg} / \mathrm{m}^{3}$, thickness $200 \mathrm{~mm}$, thermal conductivity under operating conditions $\left.\mathrm{B}\left(\lambda_{\mathrm{B}}\right)-1.86 \mathrm{~W} /\left(\mathrm{m}^{\circ} \mathrm{C}\right)\right)$.

Facade insulation system (SFTC) along the surface of the walls: mineral wool slab with a density of $80 \mathrm{~kg} / \mathrm{m}^{3}$, thickness of $\left.100 \mathrm{~mm}, \lambda_{\mathrm{B}}-0.46 \mathrm{~W} /\left(\mathrm{m}^{\circ} \mathrm{C}\right)\right)$. The basement part is made of extruded polystyrene foam (XPS-plates) $100 \mathrm{~mm}$ thick at a height of $1 \mathrm{~m}$ from the bottom edge of the wall above the ventilated space. XPS-boards with a density of $30 \mathrm{~kg} / \mathrm{m}^{3}$, with a thickness of $50 \mathrm{~mm}$ each layer $\lambda_{\mathrm{B}} 0.031 \mathrm{~W} /\left(\mathrm{m}^{\circ} \mathrm{C}\right)$ XPS-plates over cold.

The insulation of the overlap was carried out over the ventilated space made of rolled polyethylene foam with a metallized coating $20 \mathrm{~mm}$ thick, with a density of $30 \mathrm{~kg} / \mathrm{m}^{3}, \lambda_{\mathrm{B}}$ $0.032 \mathrm{~W} /\left(\mathrm{m}^{\circ} \mathrm{C}\right)$. On top of the overlap, two layers of XPS-plates were laid (in a spaced manner with displaced joints) and a layer of rolled polyethylene foam, which was put of the wall $(100 \mathrm{~mm})$ with mechanical fastening and welded into a seamless insulating shell.

With the help of the THERM computer program, the conditions of two-dimensional heat transfer in the enclosing structures of a pile building were simulated. The construction of such buildings is practiced on problem soils. Structures were taken as the basis for the calculation, the nodes of which are shown in Fig. 2 and 3.

The resulting models were analyzed in terms of the thermophysical characteristics of the structures. As a result, the optimal version of the insulation system was chosen, which is effective both in the climatic conditions of the middle zone and in the especially cold conditions of Yakutia and the Arctic.

\section{Discussions}

Modeling shows that in the places where the structure rests on the column, in view of the high thermal and thermal diffusivity of the supporting structures, a "temperature bridge" is preserved, passing through the contact points of structural elements ("column - strapping load-bearing wall). At the same time, the placement of rolled polyethylene foam on the 
outer insulated surface (above the cold space under the structure) and as an element of the floating floor inside the room, allows you to completely block possible paths of heat loss both due to the "temperature bridge" and due to the blocking of direct infiltration of cold air along joints of structures (Fig. 1,2).

The effect of a higher level is manifested in the area between the columns, where the use of combined insulation (panel extrusion polystyrene (XPS) or polyisocyanurate foam (PIR) with a contour protection from rolled polyethylene foam) allows a completely seamless insulation shell to be formed (Fig. 3).

Thus, the proposed design solutions based on the use of a combined insulation system make it possible to form an insulating shell that meets the requirements of both heat conservation and energy efficiency.

The effect of using this system solution increases if structures operating in conditions of significant negative temperatures are insulated (Fig. 3). It should be noted that the studies carried out at the NRU MSCU [15-17] showed that all insulating materials can operate at temperatures up to minus $80{ }^{\circ} \mathrm{C}$ without loss of properties and thermal insulation ability.
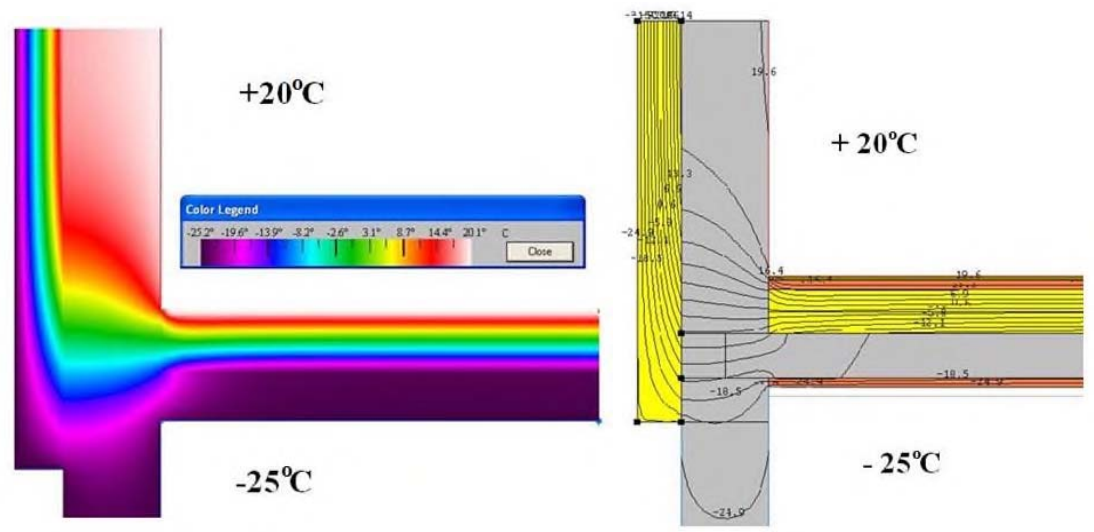

Fig. 2. The structure of the formation of the temperature field in a structure partially insulated above the ventilated space: $a$ - visualization of the temperature field; $b$ - graphic interpretation of the temperature distribution (Moscow, Moscow region. Leaning on a column).
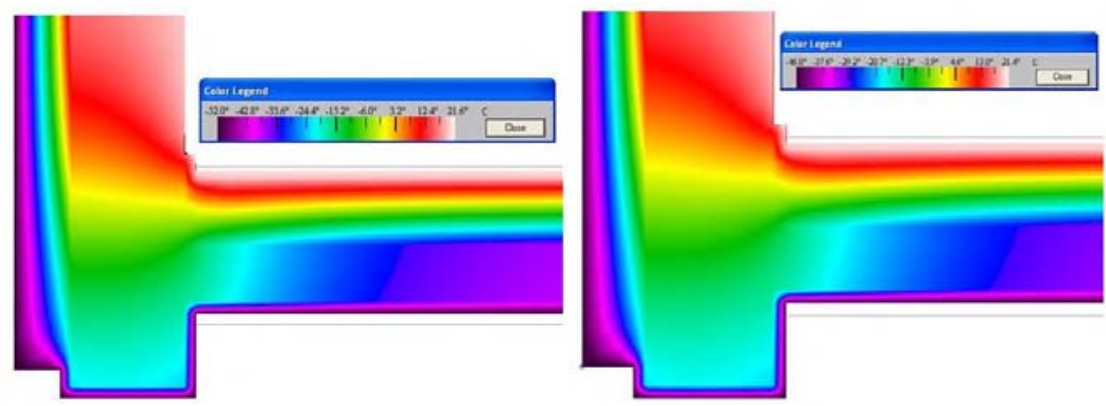

Fig. 3. The structure of the formation of the temperature field in the structure isolated above the ventilated space (between the support columns): a - visualization of the temperature field for Yakutsk (cold - $52{ }^{\circ} \mathrm{C}$ ); $\mathrm{b}$ - visualization of the temperature field for Norilsk (cold $-46^{\circ} \mathrm{C}$ ).

The operating conditions of thermal insulation based on extruded polystyrene foam, polyisocyanurate foam and polyethylene foam are quite consistent with the studied ranges of operation of these materials and their operational resistance, which assumes the 
possibility of long-term operation of the insulation system. The developed insulation systems for building structures allow achieving the standard thermal resistance, minimizing possible heat transfer bridges.

In construction, the following types of building systems are implemented: a composite fa-cade thermal insulation system (SFTC), a ventilated facade system (SVF), a layered masonry system (SLM), a translucent facade system (SFT), frame structures. A group of building systems, implemented in pile structures, which are used especially widely on soft soils or in permafrost conditions, is located separately.

The development of the northern territories is relevant for the development of all countries bordering the Arctic regions. For Russia, these regions are of particular importance in view of the expediency of developing the Northern Sea Route, increasing the country's defense capability, exploration and production of oil and gas on the shelf of the northern seas, as well as the extraction of other minerals. The development of the northern territories, from the standpoint of construction, involves the implementation of the following tasks:

- construction of buildings and structures that provide heat conservation, comfortable indoor conditions and the possibility of implementing technological processes (which also requires positive temperatures);

- development of road infrastructure taking into account the preservation of permafrost and taking into account the presence (or formation during thawing) of weak soils.

Materials for insulation systems of buildings and structures for northern latitudes must have not only low thermal conductivity, vapor and water permeability, but also resistance to aggressive environments and resistance to groundwater.

Foamed plastics are most suitable for the structures under consideration, namely products based on extruded polystyrene foam (XPS-plates) and polyethylene foam (PEproducts). Thermal insulation products based on these polymers have low thermal conductivity and vapor permeability, high resistance to moisture and the whole complex of frost factors. XPS-boards have greater rigidity and resistance to mechanical stress and are used in the construction of road foundations and facade systems with plastering (SFTC). PE-products (mats or rolls) are elastic material that allows insulating surfaces of complex configuration and allowing a seamless welded joint.

\section{Conclusion}

The operating conditions of thermal insulation based on extruded polystyrene foam, polyisocyanurate foam and polyethylene foam are quite consistent with the studied ranges of operation of these materials and their operational resistance, which assumes the possibility of long-term operation of the insulation system. Rolled polyethylene foam with a metallized coating, forms a seamless insulating shell, completely blocks the possible paths of cold air infiltration at the joints of the structural elements, thereby reducing possible heat losses.

Using the program makes it possible to simulate 2D heat transfer in building components such as windows, walls, floors, roofs and doors. The analysis of heat transfer using the program allows you to evaluate the energy efficiency of the structure and the local temperatures of the sample, allowing you to solve problems with condensation, moisture content of the structure material and its tightness.

Calculation of temperature fields using the THERM computer program showed that the developed insulation systems for building structures allow achieving the standard thermal resistance, minimizing possible heat transfer bridges. 


\section{References}

1. A. D. Zhukov, K. A. Ter-Zakaryan, D. U. Tuchaev, et al., International Agricultural Journal, 1 (361), 65-67 (2018)

2. E. A. Zinovieva, A. D. Zhukov, A. K. Ter-Zakaryan, et al., Housing 7, 35-40 (2019) DOI: https://doi.org/10.31659/0044-4472-2019-7-35-40

3. A. D. Zhukov, K. A. Ter-Zakaryan, V. S. Semenov, et al., Insulation systems for buildings and structures based on polyethylene foam, IPICSE-2018 (2018) DOI: https://doi.org/10.1051/matecconf/201825101014

4. A. D. Zhukov, K. A. Ter-Zakaryan, V. S. Semenov, ScienceDirect IFAC PaperOnLine 51(30), 803-807 (2018) DOI: 10.1016/j.ifacol.2018.11.191

5. R. S. Fedyuk, A. V. Mochalov, V. A. Simonov, Bulletin of the Engineering School of the FEFU 2 (11), 39-44 (2012)

6. N. P. Umnyakova, V. M. Tsygankov, V. A. Kuzmin, Zhilishchnoe Stroitel'stvo 1-2, 38-42 (2018)

7. I. Ya. Gnip, V. I. Kerchulis, S. Y. Vaitkus, Stroitel'nye materialy 12, 40-44 (2012)

8. N. P. Umnyakova, I. V. Bessonov, A. D. Zhukov, et al., MATEC Web of Conferences (ICMTMTE 2019). Published online: 18 November (2019) DOI: https://doi.org/10.1051/matecconf/201929800013

9. P. Gudkov, P. Kagan, A. Pilipenko, et al., Usage of thermal isolation systems for lowrise buildings as a component of information models 01039, published online: 29 May (2019) DOI: https://doi.org/10.1051/e3sconf/20199701039

10. P. M. Zhuk, A. D. Zhukov, Ecology and industry of Russia 4, 52-57 (2018)

11. A. D. Zhukov, K. A. Ter-Zakaryan, I. V., Bessonov, et al., Building Materials 9, 58-61 (2018)

12. A. D. Zhukov, K. A. Ter-Zakaryan, I. V. Bessonov, et al., Building Materials 6, 49-55 (2019) DOI: https://doi.org/10.31659/0585-430X-2019-771-6-49-55.

13. S. Kozlov, B. Efimov, et al., Optimization of foamed plastic technology, 06010, published online: 29 May (2019) DOI: https://doi.org/10.1051/e3sconf/20199706010

14. V. S. Semenov, I. V. Bessonov, K. A. Ter-Zakaryan, et al., Regional Energy Problems 4 (2020) DOI: 10.5281/zenodo.4018999 UDC: 691.1752./6./8

15. A. Zhukov, T. Dovydenko, S. Kozlov, et al., Innovative technologies for low-rise construction, TPACEE 2018, 02032, published online: 02 April (2019) DOI: https://doi.org/10.1051/e3sconf/20199102032

16. A. D. Zhukov, K. A. Ter-Zakaryan, E. Yu. Bobrova, Moscow Economic Journal (QJE.SU) 5 (2018)

17. E. Bobrova, A. Pilipenko, A. Zhukov, Insulating sheath system and energy efficiency of buildings, TPACEE 2018, 02019, published online: 02 April (2019) DOI: https://doi.org/10.1051/e3sconf/20199102019 